\title{
A suggested site for the implantation of myocardial pacemakers in infants and young children
}

\author{
FA Y E K D. SA L A M A \\ St. George's Hospital, London, and The Western Hospital, Southampton
}

\begin{abstract}
Salama, F. D. (1976) Thorax, 31, 346-349. A suggested site for the implantation of myocardial pacemakers in infants and young children. A new site for burying an implantable pacemaker in infants and young children is described. The Medtronic sutureless screw electrode is applied to the diaphragmatic surface of the heart through a transxiphoid approach. The unit is inserted in the abdominal wall between the transversalis fascia and the transversus muscle. The method is simple, taking approximately $\mathbf{3 0}$ minutes to complete. It avoids thoracotomy. The unit is well concealed and protected. The coils of the lead are relatively free from adhesions and allow for growth in the child.
\end{abstract}

Heart block in children commonly presents as a congenital defect or is surgically induced. Permanent pacing in this age group using an implantable pacemaker is difficult because of the size of the unit relative to the child and the need to allow for rapid growth once the lead is in position.

The myocardial electrode is usually inserted through a left thoracotomy incision. The unit is either buried in the subcutaneous tissue of the abdominal wall (Harris, Bowman, and Griffiths, 1966; Martin et al., 1966; Trusler, Mustard, and Keith, 1968; Siddons, 1971; Idriss et al., 1973), between the abdominal muscles (Lillehei et al., 1963), in the rectus sheath (Williams and Campbell, 1969) or within the thoracic cavity (Khan et al., 1965; Escano et al., 1971).

This paper describes a simple technique using the Medtronic sutureless screw electrode and inserting the unit in the abdominal wall anterior to the transversalis fascia.

\section{OPERATIVE TECHNIQUE}

An $8 \mathrm{~cm}$ midline upper abdominal incision is made caudally from the xiphisternum. The linea alba is divided but the peritoneum is left intact. The xiphoid process is cleared of all its attachments and is excised. The anterior fibres of the diaphragm are divided to expose the inferior surface of the pericardium, which is then opened transversely for about $3 \mathrm{~cm}$, avoiding both pleurae. The sternum is then lifted forwards and the diaphragm is depressed, thus exposing a wide area of the anterior and diaphragmatic surfaces of theo right ventricle. In postoperative cases, some dis- $\triangle$ section is needed to free a part of the inferior surface of the heart.

An area of myocardium is chosen on the inferior surface of the heart which is free from fat and? coronary vessels. The heart is steadied with two fingers, and the screw electrode (Fig. 1) is applied?

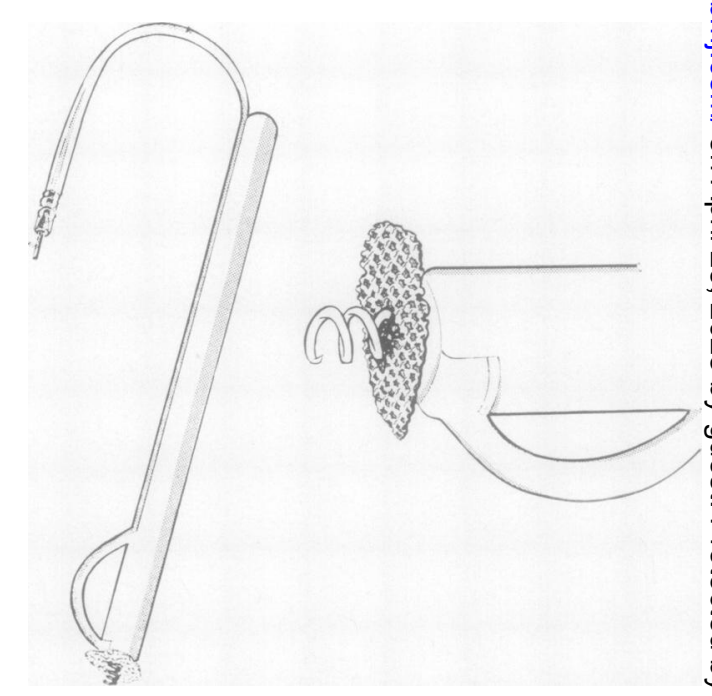

FIG. 1. Medtronic sutureless electrode on its holder. Inse shows screw end and flange. 
firmly to the chosen spot and turned in a clockwise direction for three and a half turns until the flange rests on the surface of the heart. Occasionally an extra turn is needed to achieve this. The lead is then connected to an external pacemaker and a threshold is determined.

Attention is now directed at preparing the pocket for pacemaker implantation. The left lip of the linea alba is pulled forwards to expose the posterior surface of the left rectus sheath, which is then incised longitudinally $1 \mathrm{~cm}$ from the edge (Fig. 2). The rectus muscle is retracted forwards. At the lateral edge of the sheath the fibres of the transversus are encountered. These are carefully severed from the aponeurosis to enter the space between the belly of the muscle and the transversalis fascia. The fascia is separated from the muscle by blunt and sharp dissection.

At the costal margin the costal origin of the transversus is divided, and the diaphragmatic fascia is separated from the undersurface of the diaphragm by blunt and sharp dissection. The pocket will thus be bound in its upper third anteriorly by the rectus muscle, the diaphragm, and costal margin and posteriorly by the posterior rectus sheath and diaphragmatic fascia. In its lower two-thirds it will be bound anteriorly by the rectus and transversalis muscles and posteriorly by the posterior rectus sheath and the transversalis fascia (Fig. 2).

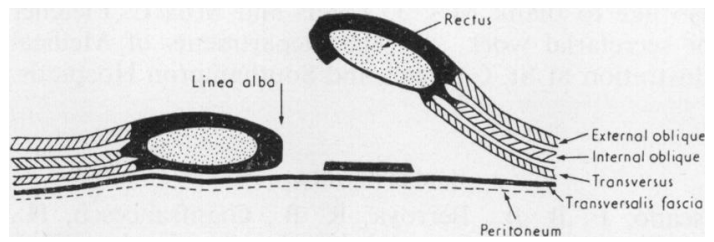

FIG. 2. Boundaries of the lower two-thirds of the pocket for implantation of the pacemaker.

The pocket should be big enough to accommodate the unit comfortably with the edge of the linea alba overhanging.

Devices demand units measuring $7.5 \times 5 \mathrm{~cm}$ were used in this series. The junction of the lead to the unit was sealed with medical adhesive. After haemostasis is ensured, the unit is placed in the pocket with the indifferent plate facing posteriorly to prevent triggering the muscle. The lead is looped once inside the pericardium and the rest is coiled behind the unit (Fig. 3). Where there are dense intrapericardial adhesions the looping of the lead in this space is omitted.

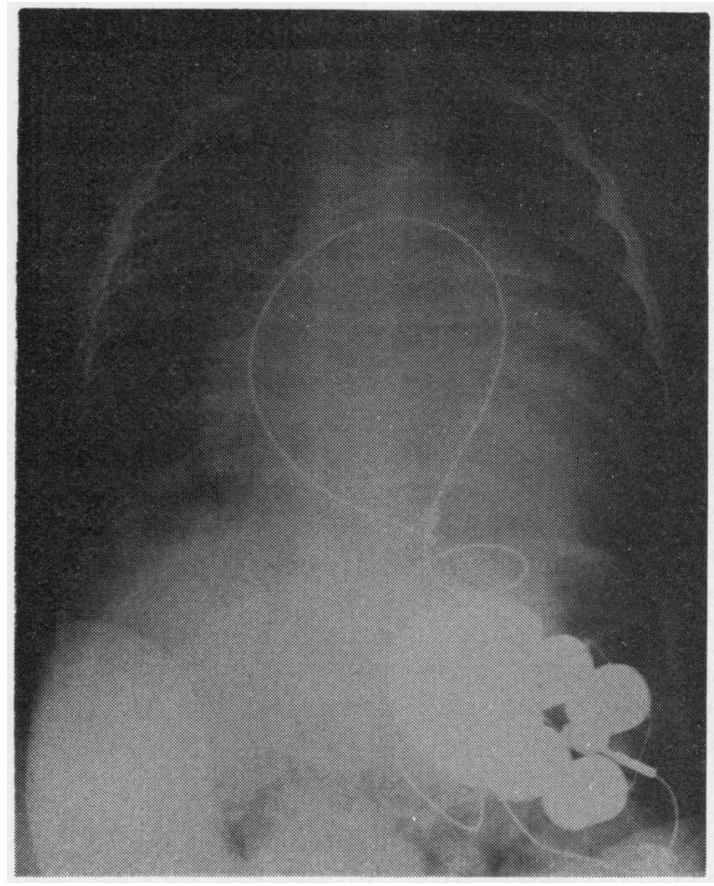

FIG. 3. Case 1. Chest radiograph showing the unit in place. The lead is looped once inside the pericardium and the rest is coiled behind the unit.

The wound is closed with monofilament nylon sutures.

\section{CASE REPORTS}

CASE 1 Congenital heart block was diagnosed postnatally in a male infant who was discharged from hospital after 10 days. At the age of 2 months he developed heart failure. Cardiac catheterization was undertaken at the age of 5 months in December 1972. The heart was found to be enlarged but without structural abnormality. He responded to therapy and remained well until August 1973 when he had an attack of unconsciousness. He had further episodes and pneumonia in December. A diagnosis of StokesAdams attacks was made and he was admitted to St. George's Hospital. In hospital he developed runs of ventricular tachycardia and fibrillation with periods of asystole. A myocardial pacing system was inserted as an emergency in December 1973. The threshold was 0.5 volts. Postoperatively he was ill with bilateral pneumonia but recovered satisfactorily. He was last seen in December 1974 and was leading a normal life. A radiograph showed the unit in place. 
The site of the unit was apparent as a slight bulge in the left hypochondrium.

CASE 2 A boy aged 3 years was noticed to have a cardiac murmur in infancy. A clinical diagnosis of ventricular septal defect was made and confirmed by cardiac catheterization at the age of 2 years.

At operation on 20 June 1974, a large infracristal VSD was closed with a Dacron patch. Complete heart block was noted on discontinuing bypass. Temporary pacing wires were inserted and postoperative pacing was instituted. The patient had an idioventricular rhythm of $45 / \mathrm{min}$.

A myocardial pacing system was inserted in July 1974. The threshold was 0.4 volts. The patient was leading a normal life in May 1975. The unit was invisible.

CASE 3 In a girl aged 7 years a cardiac murmur was noticed in infancy and a clinical diagnosis of ventricular septal defect was made. This was confirmed by cardiac catheterization.

Operation was undertaken on 12 September 1974. A large VSD of unusual anatomy was found. One papillary muscle arose in the left ventricle and crossed the defect to be inserted in the septal leaflet of the tricuspid valve. The defect was closed with a Dacron patch. On coming off bypass the heart started beating in sinus rhythm. After a short period this was followed by atrioventricular dissociation. A further period of sinus rhythm was noted but complete heart block followed. Temporary pacing wires were inserted and postoperative pacing was instituted. The patient had an idioventricular rhythm of $62 / \mathrm{min}$. A myocardial pacing system was inserted on 8 October 1974 . The threshold was 0.4 volts. The patient was leading a normal life in June 1975. The unit was not visible.

\section{DISCUSSION}

The technique of inserting the sutureless myocardial electrode in adults was described by Mansour, Fleming, and Hatcher (1973). Its use in children has not been described before. It is easier to insert than the conventional myocardial electrode, which necessitates placement of sutures and incision of the myocardium to accommodate the stimulating tip. Siddons (1971), in an attempt to avoid some of the difficulties attending insertion of such electrodes and to avoid thoracotomy, advocated transvenous pacing in children.

Left thoracotomy is the usual approach in this age group. This, however limited, is a major undertaking in a sick child. In case 1 , the patient having bilateral pneumonia, thoracotomy was inadvisable. The transxiphoid route avoids transgressing either pleur or peritoneum.

Placing the unit in the subcutaneous tissue of the abdominal wall has disadvantages. The unit i\& relatively unprotected and is liable to knocks, often preventing the child from leading a fully active life The unit also tends to migrate in the loose sub $\overrightarrow{\vec{\omega}}$ cutaneous tissue and therefore pulls on the lead. The overlying skin tends to ulcerate. The unsightl $\overrightarrow{\mathrm{R}_{\mathrm{x}}}$ protuberance can be an embarrassment to the child $\mathrm{\omega}$

In the present method, the unit is concealed and protected in a fasciomuscular plane. No migration was observed. The child is usually unaware of it presence and leads a normal and active life.

Allowing for growth could be a problem. In the transvenous method Siddons (1971) found it neces sary to operate periodically to feed more wire into the neck vein. A practical difficulty was the entrap $\overrightarrow{0}$ ment of the coiled wire in the subcutaneous tissue oิ necessitating a delicate dissection to free it.

In the present method the site of the unit is close to the tip of the electrode, leaving the entire lengths of the lead available for growth. The coils of the wire in the fasciomuscular plane are relatively free fromb adhesions and straighten out with growth.

I thank Mr. A. H. M. Siddons and Mr. J. K. Ross for allowing me to operate on patients under their care and for their valuable comments on the typescript. I shouldalso like to thank Mrs. J. Toplis and Miss E. Fletcher for secretarial work, and the Departments of Medica? Illustration at St. George's and Southampton Hospitals?

\section{REFERENCES}

Escano, F. B. Jr., Berroya, R. B., Gianfrancesco, H., Macasaet, R. A., and Khicha, G. C. J. (1971)? Intrapleural pacemaker generator in children Journal of Thoracic and Cardiovascular Surgery, 62 ? 454.

Harris, P. D., Bowman, F. O. Jr., and Griffiths, S. P. (1966) Implantation of a synchronous pacing unit in seven-month-old infant. Journal of Thoracic and Cardiovascular Surgery, 52, 277.

Idriss, F. S., Otto, R., Nikaidoh, H., Newfeld, E., and Paul, M. H. (1973). Implantation of permanent pacemaker in the first month of life for congenitaE complete heart block. Journal of Thoracic and Cardiovascular Surgery, 65, 851.

Khan, D. R., Stern, A., Sigmann, J., and Sloan, H. (1965) An emergency method of handling broken pacemaker wires in children. American Journal of Cardiology, 15 404.

Lillehei, C. W., Sellers, R. D., Bonnabeau, R. C., Jr., and Eliot, R. S. (1963). Chronic post-surgical completo heart block. Journal of Thoracic and Cardiovascular Surgery, 46, 436. 
Mansour, K. A., Fleming, W. H., and Hatcher, C. R., Jr. (1973). Initial experience with a sutureless screw-in electrode for cardiac pacing. Annals of Thoracic Surgery, 16, 127.

Martin, M. V., Lime, A. B., Almeida, C. S., Geretto, P. Del Nero, R., Monfort, J., De G. Santos, R., and Felipozzi, H. J. (1966). Implantation of ChardackGreatbatch adjustable rate and current pacemaker in a 4-month-old infant. Paediatrics, 37, 323.

Siddons, H. (1971). Transvenous pacing in the child. Annales de Cardiologie, 20, 445.
Trusler, G. A., Mustard, W. T., and Keith, J. D. (1968). The role of pacemaker therapy in congenital complete heart block. Report of 3 cases. Journal of Thoracic and Cardiovascular Surgery, 55, 105.

Williams, G. D. and Campbell, G. S. (1969). Pacemaker installation in the paediatric patient: an improved technique. Surgery, 66, 412.

Requests for reprints to: F. D. Salama, FRCS, St. George's Hospital, Hyde Park Corner, London SW1 7EZ. 